\title{
Contexto social, atuação e imagem pública de uma atriz no teatro brasileiro na virada do século XIX: Cinira Polonio ${ }^{1}$
}

Angela de Castro Reis ${ }^{2}$

A partir do exame de iniciativas como o movimento sufragista, os salões literários e a imprensa feminista brasileiros, o presente artigo analisa a carreira da atriz, dramaturga, dona de companhias teatrais, compositora e maestrina Cinira Polonio (1857-1938), cuja liberdade pessoal e independência, aparentemente incomuns em sua época, já eram compartilhadas com algumas de suas contemporâneas.

Palavras-chave: Teatro brasileiro; Atrizes brasileiras; Feminismo.

\section{Abstract}

From the examination of initiatives such as the suffragist movement, the literary halls and the Brazilian feminist press, this article analyzes the career of the actress, playwright, owner of theater companies, composer and female conductor Cinira Polonio (1857-1938), whose personal freedom and independence, apparently unusual in her time, were already shared by some of her contemporaries.

Keywords: Brazilian theater; Brazilian actresses; feminism.

1 A versão original deste texto foi apresentada em comunicação no I Encontro e Congresso de Performance e Política das Américas, evento realizado na UNIRIO em 2000.

2 Doutora em Teatro (UNI-RIO), professora Adjunta da Escola de Teatro da UFBA, cumprindo Acordo de Colaboração Técnica junto à UNIRIO (2012-2014). Autora dos livros Cinira Polonio, a divette carioca: estudo da imagem pública e do trabalho de uma atriz no teatro brasileiro da virada do século XIX e A tradição viva em cena: Eva Todor na Companhia Eva e seus artistas (1940-1963). 
$\mathrm{N}$ ascida no Rio de Janeiro, a hoje inteiramente desconhecida atriz, dona de companhias teatrais, autora teatral, compositora e maestrina Cinira Polonio (1857-1938) desfrutou de muito sucesso nas duas primeiras décadas do século $X X$, ocupando, entre tantas atividades de destaque, o posto de primeira atriz na Companhia de Revistas e Burletas do Teatro São José, uma das mais importantes do chamado "teatro ligeiro" no Rio de Janeiro (Chiaradia, 2012). Além da carreira diversificada, chamam a atenção algumas de suas características pessoais: $o$ exercício de funções habitualmente exercidas por homens; o fato de jamais ter se casado, tendo, ao contrário, uma vida amorosa movimentada; suas constantes viagens pelo Brasil e pela Europa, que reforçam uma imagem de liberdade pessoal e independência bastante incomum em mulheres de sua época.

No entanto, se analisado segundo uma visão feminista da história do teatro (Aston, 1995) (Davis, 1991) e a partir de um contexto social mais amplo, percebe-se que o comportamento ousado da atriz - semelhante ao da compositora Chiquinha Gonzaga, consagrada no imaginário popular brasileiro como uma transgressora dos padrões sociais determinados para a mulher no fim do século XIX e início do século XX (Diniz, 1991) - já era compartilhado com algumas de suas contemporâneas.

No fim do século XIX, a participação da mulher na sociedade brasileira, até então restrita a uma função familiar - centrada na educação dos filhos e na administração do lar - começa a se transformar, a partir do incremento na participação do mercado de trabalho. Novidades tecnológicas, como o bonde, também possibilitaram a saída de mulheres do espaço restrito da casa para as ruas. Assim, entre tantas outras consequências, as grandes mudanças políticas e sociais do Brasil na virada do século - entre as quais a Abolição da Escravatura e a Proclamação da República - foram fundamentais também para modificar o papel da mulher na sociedade.
Neste momento, mulheres que podemos denominar como "pré-feministas" uma vez que o movimento feminista só se constitui com esta denominação no Brasil na segunda metade do século $X X$ - criaram iniciativas pioneiras, como o movimento sufragista, os salões literários e a imprensa feminista. Foram inúmeros os jornais editados por mulheres no século XIX, entre os quais podemos citar O Jornal das Senhoras, lançado no Rio de Janeiro em 1852; O Bello Sexo, publicado em 1862, no Rio de Janeiro; $O$ Domingo, de propriedade de Violante de Bivar e Vellasco, e O Jornal das Damas, ambos publicados em 1874, no Rio de Janeiro; Myosotis, de Maria Heraclia, lançado em Recife em 1875; Echo das Damas, de Amélia Carolina da Silva Couto, lançado no Rio de Janeiro em 1879; O Direito das Damas, de Idalina d'Alcântara Costa, no Rio de Janeiro em 1882; A Família, de Josefina Alvares de Azevedo, iniciado em São Paulo em 1888 e transferido para o Rio de Janeiro no ano seguinte; A Mensageira, dirigido por Presciliana Duarte de Almeida em São Paulo em 1897 (Hahner, 1981, p. 52, p.61-62) (Hahner, 1978, p. 79-84) (Paixão, 1997, p. 33-37).

Entre os mais combativos, $\mathrm{O}$ Sexo $\mathrm{Fe}$ minino, editado em 1873, dirigia-se diretamente às mulheres, esforçando-se para alertá-las quanto às suas condições, necessidades e potencial. Francisca Senhorinha da Mota Diniz publicou o jornal pela primeira vez em Campanha, Minas Gerais, em 1873, onde alcançou a tiragem de 800 exemplares, número considerável em relação à população feminina alfabetizada da cidade, de 1.458 mulheres. Em 1875 o jornal foi transferido para o Rio de Janeiro, onde, apesar de inúmeras dificuldades, resistiu até 1876. Suspenso nesta data, passaram-se quatro anos até que a editora começasse outro jornal no Rio de Janeiro: Primavera surgiu em 1880, mas logo desapareceu, seguido do também efêmero $\mathrm{Voz}$ da Verdade, em 1885. Em 1889, O Sexo Feminino ressurge, encontrando mais sucesso que antes e alcançando 2.400 exemplares. Imediatamente após a proclamação da República, Francisca Diniz muda o nome do 
jornal para O Quinze de Novembro do Sexo Feminino, "simbolizando sua determinação para ganhar liberdade e direitos políticos plenos para as mulheres". (Hahner, 1981, p.60-61)

Ainda no século XIX, os salões literários foram também um importante instrumento de socialização das mulheres (Paixão, 1997, p. 159-186), que passavam de meras consumidoras a produtoras de cultura. Criados a partir da grande influência da cultura francesa no Brasil - graças à qual o idioma e a literatura franceses eram familiares às jovens da elite - os salões cariocas, que no início, eram um espaço no qual as jovens de famílias abastadas podiam tornar públicos seus dotes artísticos - um dos atributos necessários a um bom casamento -, tornaram-se, durante o Império, instâncias de mediação entre a burguesia e a aristocracia, num espaço onde a alegria e a informalidade quebravam as barreiras de classe e poder.

No início do século $X X$, adquiriu força a luta pelo voto feminino, iniciada ainda no século XIX. O movimento sufragista brasileiro, tendo Berta Lutz - bióloga e advogada de São Paulo e primeira mulher a alcançar posição de destaque no Museu Nacional do Rio de Janeiro - como uma de suas líderes, prosseguiu em sua campanha pelo voto, organizando no Rio de Janeiro, em 1922, o Primeiro Congresso Internacional Feminino. Finalmente, um novo código eleitoral foi estabelecido por um decreto de 24 de fevereiro de 1932 - confirmado pela Constituição de 1934 -, garantindo então o voto às mulheres (Hahner, 1978).

A partir desta contextualização, Cinira Polonio e Chiquinha Gonzaga - um propalado exemplo de "mulher à frente de seu tempo" no imaginário brasileiro - são compreendidas não como seres excepcionais, precursoras que derrubaram sozinhas os grilhões que acorrentavam as mulheres no século XIX, mas como mulheres que, embora tendo um comportamento de destaque, só puderam exercê-lo porque, de alguma maneira, ele já vinha sendo preparado por um grande número de mulheres, que se movimentavam igualmente em novos papéis na sociedade.

No entanto, a luta das mulheres por novos espaços na sociedade foi duramente combatida não apenas no Brasil como em muitos países. Na Inglaterra Vitoriana, por exemplo, as feministas foram chamadas de "galinhas a cacarejar, hommes-femmes, hermafroditas, [...] entre outros pesados epítetos sexuais" (Soihet, 1996, p.99-100), revelando um grande pavor por parte de seus detratores de que a implantação das propostas feministas tivesse como consequência uma inadmissível confusão de papéis.

Também no Brasil as reivindicações das mulheres por mais direitos deram lugar a forte oposição: em toda Primeira República o direito ao voto foi veementemente combatido por autoridades, políticos em geral e juristas, com base na diferença biológica entre homens e mulheres. $\mathrm{Na}$ imprensa, na literatura, no teatro, as feministas foram ridicularizadas e representadas como masculinizadas, feias, despeitadas, e mesmo amorais. Neste momento, em que o casamento - e a necessária e esperada maternidade - era visto como a única aspiração legítima para as mulheres, o celibato era o castigo para as que tivessem atitudes impróprias (Soihet, 1996, p.106).

Cinira Polonio, no entanto, jamais se casou, tendo, no entanto, amantes ou namorados. Curiosamente, nunca nenhum cronista ou jornalista pareceu dar maior importância a este aspecto de sua vida, sobre o qual existem pouquíssimos comentários. Lafayette Silva, um dos poucos a fazêlo, se refere duas vezes ao assunto, mas de maneira muito superficial: em Artistas de outras eras, comenta que "um motivo do coração forçou Cinira Polonio a deixar o Teatro Santana e o Rio de Janeiro, em fins de 1888"; em seguida, trasncreve um comentário de Fialho de Almeida, escritor português, que se refere à "louca variabilidade amorosa" da atriz. ${ }^{3}$

A única exceção a esta regra é um artigo de setembro de 1905 da revista O

3 [...] essa brasileira de Paris conseguiu intrometer na nossa vida de camarim, com a sua louca variabilidade amorosa, um pouco do seu rebuço [...]. (SILVA, 1939, p. 140). 
Theatro, no qual há uma referência bastante incisiva sobre a atriz em uma nota dirigida a um leitor que votou nela em um concurso para escolher "a melhor atriz de opereta":

Quem quer que seja que desde o "concurso" passado vive cabalando em favor da sra. Cinira Polonio, [...] fica prevenido de que a Sra. Cinira Polonio não é mais artista nossa; está em Portugal ou em Paris, desfrutando os cobres de um pateta que se fez estelionatário (segundo ouvimos e lemos em jornais) por causa dela e passa a vida a dizer mal do Brasil, que é sua Pátria, onde ela não pretende mais voltar... porque não há teatro nem público que a compreenda. ${ }^{4}$

Das poucas referências à vida amorosa da atriz, esta é a mais contundente. No entanto, é curioso como a ira do articulista se dirige muito mais ao que ele considera desprezo, pela mesma, ao teatro e ao público brasileiros - e por extensão, ao próprio país - do que exclusivamente ao fato de Cinira Polonio ter um amante que a sustentava, ou no mínimo gastava muito dinheiro com ela. Neste caso, a exclusão da atriz no concurso promovido pela revista e o comentário à sua vida pessoal se configura muito mais como uma retaliação pelo seu abandono do país ("não é mais artista nossa") do que uma crítica específica ao seu relacionamento amoroso.

Desse modo, chama a atenção o respeito que Cinira Polonio inspirava, e, mais ainda, a inexistência de qualquer comentário negativo sobre sua vida ou qualquer dúvida sobre sua honra, interessando saber como ela conseguiu tamanha respeitabilidade (Davis, 1991, p. 69-101) -, aferida pelos artigos a seu respeito: "Muito inteligente, instruída, viajada, seu espirito encanta e cativa pelo seu espírito culto e a sua conversação amena." ${ }^{5}$

Cinira é sempre a mesma Cinira, e

4 O Theatro, n. 16, p.20, 1a quinzena set. 1905

5 O Theatro, n. 78, 20 dez. 1907. ao contrário dos outros, parece que cada vez encanta mais. É um prazer conversar com esta artista. Discute qualquer assunto, até mesmo política. Fala vários idiomas, toca harpa, piano, compõe música, faz peças, e agora sabemos que está escrevendo uma opereta. É tão difícil no nosso meio teatral encontrar quem reúna tantos predicados! ${ }^{6}$

O que se averigua é que Cinira Polonio construiu uma imagem pública no campo artístico e na sociedade baseada na inteligência, educação/cultura e elegância (como se pode depreender nas citações acima), que a manteve incólume aos preconceitos que atingiam mulheres que se aventuravam ao mercado de trabalho ou que tinham comportamentos considerados masculinos no século XIX, bem como os associados especificamente às atrizes - tradicionalmente encaradas como prostitutas (Aston, 1995, p.29) (Davis, 1991, p.78-86) (Simmel, 1993, p.2). Tais características, em especial a elegância, foram adquiridas a partir de seu contato, desde a primeira infância, com a cultura, e mais especificamente com a moda francesa da Rua do Ouvidor, onde se situava a loja $O$ grão turco, de propriedade de seus pais, comerciantes italianos (Reis, 1999, p.23).

A elegância da atriz estava ainda em consonância com o dandismo, um dos traços do movimento decadentista, que se disseminou no Brasil com o advento da República, em 1889, a partir da qual buscou-se afirmar uma imagem de modernidade no país, "divulgando para os países civilizados uma visão ilustre e respeitável da sociedade brasileira" (Levin, 1996, p. 19-28). No entanto, a consolidação do poder republicano foi acompanhada de um descontentamento crescente com o autoritarismo do Governo e com a nova ordem política e social. À medida que se estabelecia um sistema oligárquico de poder, e se consolidavam as instituições republicanas, cresciam as manifestações de isolamento, resignação e inconformismo de alguns intelectu-

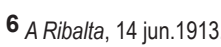


ais, bem como a tentativa de ajustamento por parte de outros, que tentavam dar uma nova utilidade ao homem ilustrado.

Uma das reações à nova ordem política e social no Brasil foi a modificação de hábitos sociais, transformados também em consequência do processo de modernização e reestruturação promovido no Rio de Janeiro: a onda de despejos no Centro atingiu a vida boêmia, desalojando os intelectuais que se reuniam nos cafés localizados no até então coração da cidade, a área circunscrita pelas ruas do Ouvidor e Gonçalves Dias. Os encontros nos cafés foram substituídos pelas reuniões fechadas nos salões, onde surgiu a moda do five o' clock tea; além disso, a vida intelectual ia se refinando também nos clubes, nos teatros da moda, nos cinematógrafos, nos hotéis, restaurantes, cassinos e music-halls, criando as condições para o aparecimento do dandismo, ideário "cujo princípio era mostrar a rebeldia de maneira intelectualmente refinada" (Levin, 1996, p.50); a noção de dandismo no Brasil, que começou a tomar forma a partir de uma reinterpretação do pessimismo europeu do fim do século - principalmente a partir da obra de Baudelaire -, passou ainda pela influência do ideário estético de Oscar Wilde: "a figura do dândi de salão, a pose arquitetada e o ranço irônico de seus paradoxos foram de repente valorizados enquanto perfil de um porta-voz do desdém pela realidade brasileira" (Levin, 1996, p. 49-72).

O espaço do dandismo era valorizado nas páginas dos jornais, em colunas ocupadas com jantares, chás, festas e atividades de lazer: "de repente, o ócio vira assunto de destaque, a moda faz notícia e os interiores das residências são priorizados nas descrições" (Levin, 1996, p. 72). A partir de uma matéria no Correio da Manhãa ${ }^{7}$, que relata uma entrevista de Cinira Polonio a um repórter, recebido na "elegante sala ricamente adornada" de sua casa na Rua do Riachuelo, podemos imaginar que a atriz, além da elegância pessoal, cultivava também o refinamento no interior de seu lar,

7 Correio da Manhã, 13 jan. 1962. Apud Artistas do passado. Revista de Teatro, Rio de Janeiro, SBAT, n. 332, p. 8-10, mar./ abr. 1963. característica exacerbada neste momento. Sua conexão com o dandismo pode ainda ser averiguada por uma declaração de Artur Azevedo acerca do modo como Cinira Polonio portava seus figurinos:

Ainda hoje, ela tornará a ser, se quiser, a "figurine" de Saxe que era na Canção de Fortúnio ou no Galo de ouro $^{8}$, porque ninguém no Rio de Janeiro (ninguém, ouviram?) soube como Cinira ajeitar a cabeleira branca, vestir a saia "à paniers", e calçar o "talon-rouge" do "dix-huitième". Parecia evadida de uma "festa campestre" de Watteau e perdida na burguesia deselegante da rua do Espírito Santo. ${ }^{9}$

Assim, fica claro como a atriz se servia com maestria dos códigos visuais do período, utilizando-os para compor uma não só uma imagem pública, como também artística, que se adequasse ao gosto do público. O comentário de Arthur Azevedo mostra claramente como essas características "pessoais" da atriz eram transportadas para o palco, moldando sua atividade como intérprete. Tal operação é comprovada pela análise dos personagens interpretados em sua carreira, bem como por inúmeros outros depoimentos de contemporâneos. Estes revelam como Cinira Polonio fazia render artisticamente sua imagem social:

[... No primeiro plano [da revista Berliques e Berloques] destaca-se Cinira Polonio, que se encarregou de doze papéis e em todos eles se mostrou radiante de mocidade e elegância. [...]

Os vestuários são ricos [...], sobressaindo os da Cinira, que das atrizes brasileiras foi sempre a que se vestiu melhor. ${ }^{10}$

Fica muito claro como a aparência pes-

8 Operetas nas quais a atriz trabalhou, após 1886, na companhia de Jacinto Heller.

9 O Paiz, 22 out. 1906; apud Artistas do passado. Revista de Teatro, Rio de Janeiro, SBAT, n. 332, p. 8-10, mar./ abr. 1963. A Rua do Espírito Santo, atual Pedro I, concentrava um grande número de teatros da cidade do Rio de Janeiro, em muitos dos quais a atriz trabalhou

10 O Theatro, n. 44, 1907 [o exemplar não especificava mês e ano]. 
soal de Cinira Polonio era um elemento fundamental do seu trabalho no palco. O último comentário do jornalista sintetiza a fusão "imagem social da atriz" / "imagem da intérprete": a elegância na vida fez de Cinira Polonio a mais elegante também nos palcos. A atriz exibia belos figurinos em todos os seus personagens, que, a partir de então, se destacavam, como a própria atriz, pelo refinamento no vestir: "Cinira Polonio, que tem o encanto da carioca e o chic da parisiense, agrada muito numa sucessão estonteante de personagens e toilettes, cada qual mais elegante e mais rica" ${ }^{11}$

A soberania de seu porte era tamanha, que transmitia elegância para todas as personagens que interpretava, fossem elas nobres ou mulheres do povo:

[...] Instintivamente aristocrática e inconfundivelmente distinta, acontece às vezes que Cinira Polonio prejudica, sem querer, a figuração dos personagens de que se incumbe, apresentando-nos campôneas, como a do Solar dos Barrigas, que parecem inscritas na carne marmórea, tecida de veias azuis das duquesas, e duquesinhas boêmias de Gerostein que parecem rainhas! ${ }^{12}$

Sendo o espelhamento na cultura europeia uma das principais características da Belle-époque ${ }^{13}$, o refinamento do vestuário de Cinira Polonio certamente atendia ao gosto de um público que pretendia viver como se estivesse na Europa: "para os brasileiros do século XIX, a Civilização era a França e a Inglaterra" (Needell, 1993, p.49). Segundo o autor, a absorção de fenômenos culturais europeus aumentou muito a partir da segunda metade do século, havendo a transformação de alguns bens culturais, como o comércio de luxo e a moda, em verdadeiros fetiches, especialmente para a população mais abastada economicamen-

11 Kosmos, n.5, s/p, maio de 1904. 0 autor do comentário se refere à participação da atriz na revista Cá e lá, de Tito Martins e Bandeira de Gouveia, no Teatro Recreio.

12 Correio da Manhã, p. 2, 01 jan. 1902. 0 texto reproduzido é a transcrição, sem indicação de fonte, de uma reportagem publicada em um jornal do exterior.

13 Considera-se belle-époque, no Brasil, o período compreendido entre 1889, com a Proclamação da República, e 1914, início da I Guerra Mundial. te. Diversos elementos da cultura europeia eram transpostos para o Brasil sem nenhuma adaptação, o que em alguns casos, como no vestuário, ocasionava um verdadeiro disparate: vestimentas de várias camadas de lã preta grossa usadas sob o sol causticante dos trópicos, num "ato vivo de autoflagelação": "na capital portuária tropical, ao longo de suas praias de areia e morros cobertos de florestas, os cariocas refaziam Paris [...]" (Needell, 1993, p. 185208). Assim, a adoção por Cinira Polonio de uma imagem francesa - elegante, refinada e dissociada da vida brasileira - encontra par no contraste entre a imagem europeia do Brasil, em especial do Rio de Janeiro, e as condições reais do país e da cidade naquele momento.

Por fim, é possível afirmar que Cinira Polonio escapou do preconceito reservado às mulheres "avançadas" graças à utilização equilibrada de elementos diametralmente opostos: por um lado, a exacerbação de características tradicionalmente associadas às mulheres, em especial a elegância; por outro, o desenvolvimento de capacidades associadas ao universo masculino de sua época, como a gerência de negócios (uma companhia de teatro), bem como a inteligência, cultura e educação. 


\section{REFERENCIAS:}

ASTON, Elaine. An introduction to feminism and theatre. London, New York: Routledge, 1995.

CHIARADIA, Filomena. A companhia do Teatro São José: a menina-dos-olhos de Paschoal Segreto. São Paulo: Hucitec, 2012.

DAVIS, Tracy C. Actresses as working women: their social identity in Victorian culture. London, New York: Routledge, 1991.

DINIZ, Edinha. Chiquinha Gonzaga; uma história de vida. Rio de Janeiro: Rosa dos Tempos, 1991.

FARIA, João Roberto (dir). História do teatro brasileiro: das origens ao teatro profissional da primeira metade do século XX. Vol. I. São Paulo: Perspectiva, Sesc São Paulo, 2012.

HAHNER, June. A mulher brasileira e suas lutas sociais e politicas: 1850-1937. São Paulo: Brasiliense, 1981.

A mulher no Brasil. Rio de Janeiro: Civilização Brasileira, 1978.

LEVIN, Orna Messer. As figurações do dândi: um estudo sobre a obra de João do Rio. Campinas: Editora da Unicamp, 1996.

NEEDELL, Jeffrey D. Belle époque tropical; sociedade e cultura de elite no Rio de Janeiro na virada do século. São Paulo: Companhia das Letras, 1993.

PAIXÃO, Sílvia. A república dos sentimentos: Revista Única (1925-27) e espaço feminino no Rio de Janeiro. Rio de Janeiro, 1997. Tese de Doutorado em Literatura Comparada. UFRJ/CLA/FL. (Mimeo)

REIS, Angela. Cinira Polonio, a divette carioca: estudo da imagem pública e do trabalho de uma atriz no teatro brasileiro da virada do século XIX. Rio de Janeiro: Arquivo Nacional, 1999.

SIMMEL, Georg. Algumas reflexões sobre a prostituição no presente e no futuro (1892). In: Filosofia do amor. São Paulo: Martins Fontes, 1993. p.1-17.

SOIHET, Rachel. Mulheres em busca de novos espaços e relações de gênero. In: Acervo; revista do Arquivo Nacional. Rio de Janeiro, Arquivo Nacional, p. 99-124, 1996. 
